\title{
RNAi genes pave their own way
}

\author{
Leonie M. Kamminga and René F. Ketting ${ }^{1}$ \\ Hubrecht Institute-KNAW, University Medical Centre Utrecht, 3584 CT Utrecht, The Netherlands
}

Heterochromatin formation in fission yeast and the role of RNAi in this process have been intensively studied. So far, however, nothing is known about the regulation of expression of RNAi components during these events. Gullerova and colleagues (pp. 556-568) reveal an autoregulatory loop that regulates the expression of RNAi genes and centromeric heterochromatin formation during the cell cycle. Gene orientation plays a surprising role in this process.

RNAi in the fission yeast Schizosaccharomyces pombe is involved in the proper functioning of centromeres, and, in the absence of RNAi, cells display major defects in chromosome segregation. In particular, RNAi is required to establish and maintain heterochromatin at the pericentromeric regions (Martienssen et al. 2005; Kloc and Martienssen 2008; Grewal 2010). In order to properly assemble this heterochromatin, different histone-modifying enzymes and the RNAi machinery are required in a coordinated fashion (Fig. 1A). dsRNAs are produced by the RNA-dependent RNA polymerase complex (RDRC; containing, amongst others, Rdp1) (Motamedi et al. 2004). Dicer (Dcr1) processes this dsRNA into siRNAs that are taken up and loaded into the argonaute protein Agol in the context of a complex named ARC (Buker et al. 2007). Ago1, loaded with this siRNA, then becomes part of another complex: the RNA-induced transcriptional silencing complex (RITS), consisting of Ago1, Chp1, and a protein named Tas3 (Motamedi et al. 2004; Noma et al. 2004; Verdel et al. 2004). RITS then targets nascent transcripts that are made at the pericentromeric loci and again recruits RDRC, establishing a feed-forward loop that amplifies the RNAi response. RITS also recruits, through the protein Stcl (Bayne et al. 2010), a complex (CLRC) containing an enzyme (Clr4) that catalyzes the methylation of Lys 9 of histone H3 (H3K9me) (Hong et al. 2005; Horn et al. 2005; Jia et al. 2005). The HP1-like protein Swi6 can bind this histone mark, resulting in heterochromatin formation (Noma et al. 2004; Motamedi et al. 2008). In addition, RITS itself binds to H3K9me through Chp1, strengthening its interaction with the targeted locus. Finally, Swi6 promotes

[Keywords: RNAi genes; autoregulation; convergent genes; fission yeast; heterochromatin]

${ }^{1}$ Corresponding author.

E-MAIL r.ketting@hubrecht.eu; FAX 31-030-2516554.

Article is online at http://www.genesdev.org/cgi/doi/10.1101/gad.2038611. further spreading of heterochromatin through the recruitment of the protein complex SHREC (Sugiyama et al. 2007). Altogether, this network of events results in compact heterochromatin formation at the pericentromeric regions.

However, this very same model also poses a problem. If the pericentromeric regions are indeed transcriptionally silenced, how can nascent transcripts be produced from them? This issue has been partly resolved by the finding that pericentromeric chromatin structure and transcriptional activity change during the cell cycle /Chen et al. 2008; Kloc et al. 2008). There is a short "window of opportunity" during the $S$ phase of the cell cycle, in which centromeric transcripts are made. This opportunity seems to arise through the displacement, just before mitosis, of Swi6 from the pericentromeric regions, triggered by phosphorylation of histone H3 on Ser 10 (H3S10). Transcriptional silencing in the first instance is maintained through the recruitment of condensin, but, after mitosis, when condensin dissociates, pericentromeric DNA becomes accessible to RNA polymerase II (Pol II). This allows the RNAi-induced heterochromatin cycle, as described above, to start over again. Initiation of this cycle may be partially assisted by low levels of Swi6 protein that remain associated with heterochromatin during mitosis (Nakayama et al. 2000). Other triggers that may help initiation are RITS complexes that remained intact during mitosis, dsRNA production through bidirectional transcription at the pericentromeric regions, or short RNA molecules (named priRNAs) that are thought to be derived from breakdown products of cellular mRNAs (Halic and Moazed 2010). These observations clearly provided great insight into the cell cycle dependence of centromeric heterochromatin, but still very little was known about the regulation of expression of RNAi components during these events.

The genome of $S$. pombe is very compact. As a result, protein-coding genes are closely spaced and transcription termination is a tightly regulated process (Bahler 2005). Still, for some convergent genes (CGs), transcripts that extend into the downstream genes have been detected (Hansen et al. 1998). One might expect that such overlapping transcripts from CGs may trigger RNAi through the production of dsRNA, resulting in noncentromeric RNAi. Indeed, there are reports on RNAi components acting at loci other than centromeres. For example, Dcr1 and Rdp1 have been found at many different genomic loci (Woolcock et al. 2011). However, even though gene silencing effects have been observed at these locations, 
A

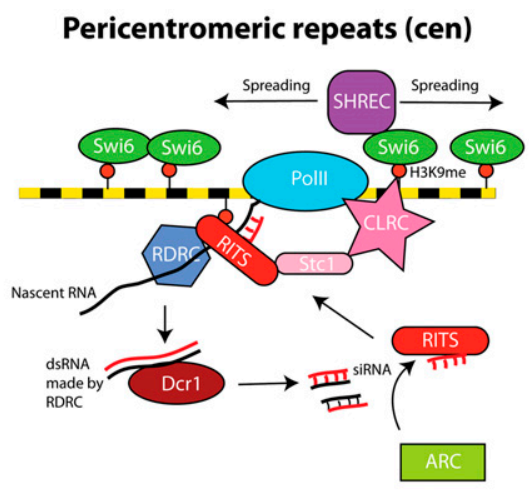

B

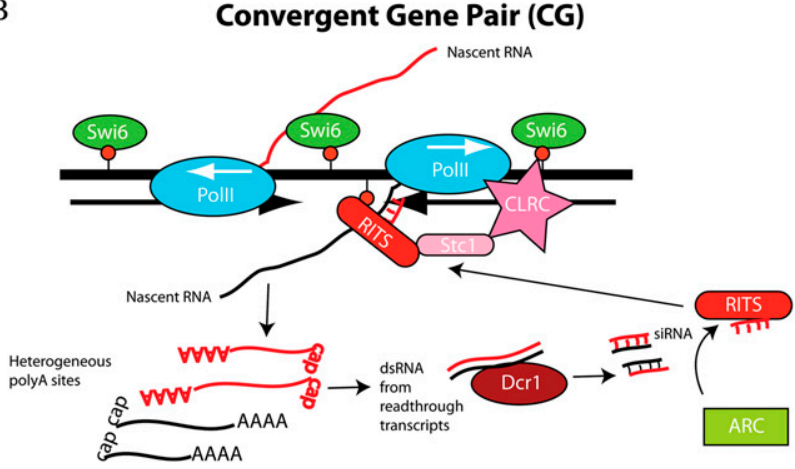

Figure 1. Models for RNAi at pericentromeric and CG loci in $S$. pombe. (A) At the pericentromeric loci, an Argonaute proteincontaining complex named RITS targets nascent Pol II transcripts and recruits an RDRC. RDRC synthesizes dsRNA that is processed by Dicer (Dcr1) into siRNAs that can associate with Agol in the context of the ARC complex. This results in the formation of another RITS complex. RITS, via the protein Stc1, also recruits the CLRC complex. CLRC promotes H3K9me, which in turn recruits HP1 homologs like Swi6. Heterochromatin can spread to adjacent sites by further recruitment of chromatin modifiers like SHREC. (B) At CG loci, bidirectional transcription of CGs leads to dsRNA formation and subsequent siRNA generation by Dcrl. RDRC does not play a significant role in RNAi at CG loci. Further mechanisms appear to be similar to those in A. Black arrows indicate CGs. White arrows in Pol II indicate direction of transcription.

heterochromatin formation does not seem to result from these interactions. Furthermore, earlier work from the Proudfoot laboratory (Gullerova and Proudfoot 2008) shows that, at CG loci at which both genes are actively transcribed at the same time, RNAi can trigger the formation of heterochromatin. Interestingly, such CGs show cell cycle-dependent expression, being down-regulated during the G1/S phase and more highly expressed during G2. The following cycle of events was suggested to be responsible for these observations. First, during G1/S, usage of distal polyadenylation (polyA) signals on transcripts from both genes in the CG pair results in complementary transcripts that may form dsRNA. This triggers an RNAi response that results in Swi6 recruitment to CG pairs (Fig. 1B). Swi6 then recruits cohesin, which starts to accumulate in between the two genes at the CG locus. This accumulation of cohesin is thought to prevent readthrough transcription by stimulating the use of more proximal polyA signals, resulting in a loss of dsRNA and consequent loss of RNAi and heterochromatin. Cohesin may bind DNA in two ways: as a very stable, tightly closed ring that encircles DNA, or in a form more dynamically associated with DNA (Hirano and Hirano 2006). Which form of cohesin plays a role in the regulation of transcription of CGs has not been determined, but a clue may come from the interesting observation that, in S. pombe, in G2, nearly $90 \%$ of detectable cohesin is located between two convergently transcribed genes (Gullerova and Proudfoot 2008). It is thought that the pushing of ring-shaped cohesin complexes along the DNA fiber by elongating Pol II causes this accumulation of cohesin between CGs at G2. This model of RNAi at CG loci would also explain why a genome-wide association study on Swi6 identified only a small number of CG pairs as bound by Swi6. As S. pombe has an extended G2 phase (Alfa et al. 1993), unsynchronized cultures of S. pombe consist mostly of cells in the G2 phase, in which only limited heterochromatin formation would be expected at CGs.

Gullerova et al. (2011) now connect the issue of regulation of the RNAi pathway to the just-described events happening at CG loci. Interestingly, they find that, in fission yeast, $\sim 80 \%$ of RNAi genes, including ago1 and $d c r 1$, are convergently transcribed, whereas random gene sets display roughly $30 \%$ CG pairs. Indeed, consistent with their previous work, these RNAi components display cell cycle-dependent expression, effectively constituting an autoregulatory loop (Fig. 2). This leads to downregulation of convergent RNAi genes in the G1/S phase of the cell cycle, and slightly more abundant RNAi components during G2. Gullerova and Proudfoot (2008) suggest that the lower abundance of RNAi components during G1/S may play a role in keeping centromeric chromatin open to allow transcription. Gullerova et al. (2011) now extend these findings by detecting siRNAs derived from targeted CG loci (CG-siRNAs). These siRNAs were detected in G1 but not in G2, consistent with the model. Even though siRNAs were convincingly identified, their abundance remained quite low compared with pericentromerederived siRNAs (cen-siRNAs). This may be linked to their surprising and yet unresolved finding that RDRC does not seem to be involved in CG-RNAi, preventing amplification of CG-siRNAs. Unfortunately, CG-siRNAs were not sequenced, preventing further, more detailed analysis on CG-siRNA generation. Finally, Gullerova et al. (2011) further support their model by taking ago1 and dcr1 out of their CG constellation. This was done by insertion of a gene (ura4) in between either ago1 or $d c r 1$ and their respective CG partner. Ura4 was placed in tandem orientation with respect to ago1 or dcr1. Strikingly, these tandemized mutants (Tago1 and Tdcr1) lose their transcriptional down-regulation during G1/S, and CG-siRNAs from the ago1 gene are undetectable in a Tago1 strain. Surprisingly, Pol II occupancy of pericentromeric regions also decreased in Tago1 and Tdcr1 strains. Interestingly, ura4 (itself a tandem-oriented gene in the wild-type situation with cell cycle-independent expression) becomes downregulated at G1/S when placed in tandem with ago1 or 


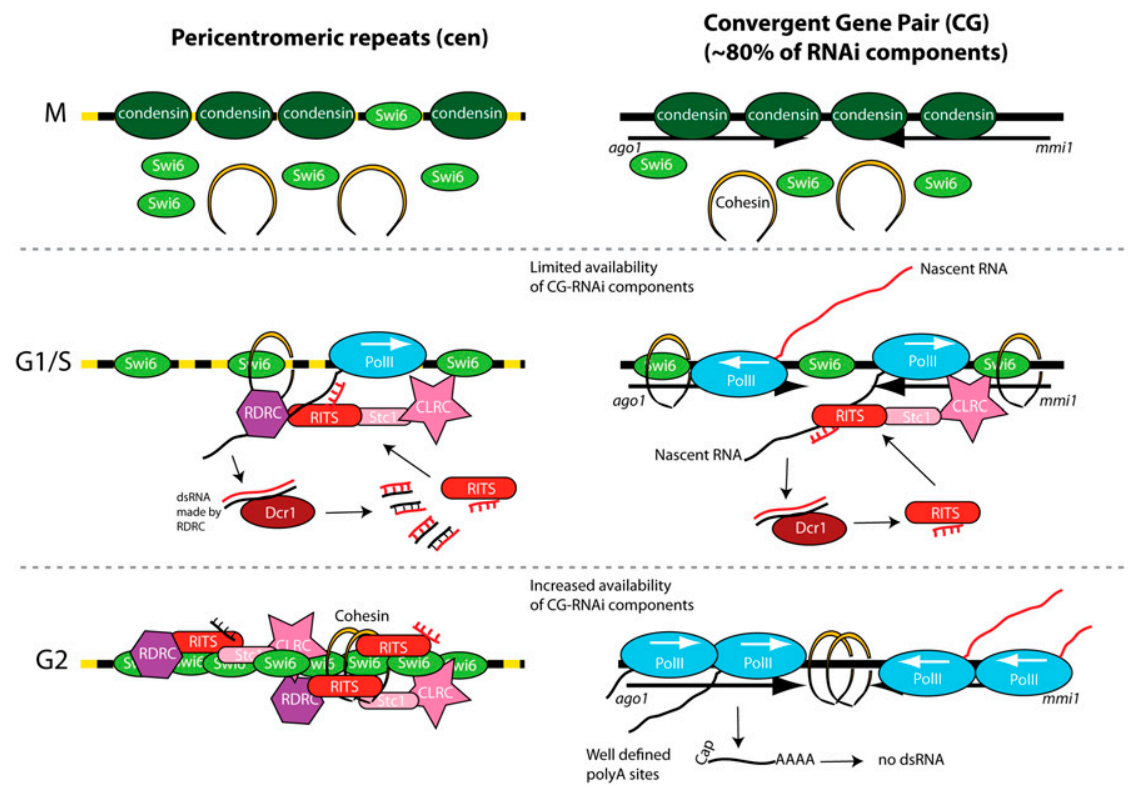

Figure 2. RNAi during the cell cycle. An overview of the autoregulatory loop of convergent RNAi genes and heterochromatin formation at the centromeres during the different stages of the cell cycle is depicted. During mitosis, H3S10 gets phosphorylated, resulting in the displacement of Swi6 with condensin. Both CGs and pericentromeric repeats are at this time covered by $\mathrm{H} 3 \mathrm{~K} 9$ me and condensin. At centromeres, Swi6 remains partly present. During G1/S, condensin delocalizes, leading to transcriptional activity. RNAi processes are triggered at both CG and centromeric loci. As the cells move into G2, the accumulated cohesin at CG loci starts to prevent dsRNA formation, and repression of CGs is relieved. These CGs include many RNAi component genes, resulting in a stronger RNAi response and further heterochromatin formation and transcriptional silencing at the centromeres. $d c r 1$, and thus in convergent orientation with the original ago1 or dcr1 partner.

These new data (Gullerova et al. 2011) provide very interesting novel insights into the dynamics of the expression of RNAi genes and heterochromatin formation in fission yeast. There are, however, still a number of puzzling aspects to these observations.

First, RDRC only has a role in the formation of centromeric heterochromatin. It remains unclear why RDRC would not act on CG loci. One might argue that rapid buildup of siRNAs at centromeric repeats is necessary to be able to quickly silence these repeats after mitosis. The cell may not want this to occur at CGs, which have to maintain transcriptional activity, albeit at a lower level during $\mathrm{G} 1 / \mathrm{S}$. Is there something that repels RDRC from CGs, or something that attracts it specifically to pericentromeric loci? In this light, the Swi6 molecules that remain associated with pericentromeric loci during mitosis (Nakayama et al. 2000) may play an interesting role.

Second, during G1/S, most cen-siRNAs are produced, while relatively little Agol is found at the centromeres, and, in G2 phase, relatively higher levels of RNAi components are observed, although no siRNAs are produced (either cen-siRNAs or CG-siRNAs). It would be interesting to study the status of Agol during the cell cycle in order to better understand this discrepancy. How much Agol is loaded with siRNAs, and what fraction is found in ARC versus RITS? Related to that, it would also be of considerable interest to closely follow both cen-siRNAs and CG-siRNAs during the cell cycle within one experiment. This may reveal subtle but important differences in expression between these two species of siRNAs, and provide information about the order in which certain events take place.

Third, to what extent are the modest changes in concentrations of CG RNAi components responsible for the observed effects on transcriptional activity of the centro- meres during the cell cycle? Or is it the titration of RNAi components to the many CG loci that is relevant for increased centromeric Pol II activity? In both scenarios, it is striking that nearly $80 \%$ of the RNAi components are found in CG orientation. Placing one rate-limiting component under CG control would seem sufficient to achieve regulation of RNAi activity, and the CG RNAi genes constitute only a small fraction of all CG pairs in total in the genome, contributing relatively little to a titration effect (although it should be noted that it is not known what fraction of CG pairs have genes that are simultaneously active).

Finally, in the study by Gullerova et al. (2011) only one CG-RNAi gene at a time was transformed into a tandem configuration. Still, this was sufficient to induce effects on centromeric transcription and cytological defects. This is surprising, as an elevated level of Agol would be expected to have an effect only if there is an excess of siRNAs that can load into the excess Agol protein, and extra Dcrl would result in a phenotype only if there would normally be enough unloaded Agol to pick them up. Clearly, both scenarios cannot be true simultaneously. This conundrum may be resolved if we take into account, as also pointed out by Gullerova et al. (2011) that Agol and Dcr1 may play a role in the cell cycle independently of their role in RNAi (Carmichael et al. 2004). Both proteins affect hyperphosphorylation of $c d c 2$ (a mitotic regulator) upon genotoxic insult, which results in cell cycle arrest. In addition, it has been shown that inappropriate cytoplasmic accumulation of Dcr1 induces cytotoxic effects that are independent of the catalytic activity of Dcr1 (Emmerth et al. 2010). These findings are poorly understood, and they need to be sorted out in more detail if we are to completely understand the phenotypes resulting from changes in the expression levels of RNAi components.

Gullerova et al. (2011) provide interesting mechanistic insights into the autoregulation of RNAi genes in a cell 
cycle-dependent manner in fission yeast, and provide evidence that gene orientation can have a profound effect on gene expression. It is, of course, interesting to speculate to what extent these observations relate to higher eukaryotes. Whether gene orientation can play an important role in other organisms is a completely open question. In the case of mammals and many other animals, we have to take into consideration that the gene density of the genome is often lower, reducing the chance for closely spaced CG pairs. Furthermore, genes behave differently in terms of transcription termination and polyA site usage, and genome-wide cohesin distribution in mammals has been shown to be very different from that in $S$. pombe (Gullerova and Proudfoot 2008; Misulovin et al. 2008; Parelho et al. 2008; Stedman et al. 2008; Wendt et al. 2008). On the other side, evidence for RNAi pathways connecting to chromatin is increasing, as was shown by work in Caenorhabditis elegans (Claycomb et al. 2009; van Wolfswinkel et al. 2009) and mammalian cells (Allo et al. 2009). However, endogenous siRNAs associated with such RNAi pathways have been detected only in $C$. elegans. Given the difficulty with which CG-siRNAs can be detected in $S$. pombe, it is conceivable that similar siRNA populations have so far escaped notice in other systems. The study by Gullerova et al. (2011) shows us that we may have to look very closely, indeed, taking into account the impacts of all possible factors that might affect the cells under study.

\section{Acknowledgments}

Work in our laboratory is supported by a VENI fellowship (91696021 to L.M.K.) from the Netherlands Organization for Scientific Research, an ERC Starting Grant from the Ideas Program of the European Union Seventh Framework Program (202819 to R.F.K.), and the European Union Sixth Framework Program Integrated Project SIROCCO (LSHG-CT-2006-037900 to R.F.K.).

\section{References}

Alfa C, Fantes P, Hyams J, McLeod M, Warbrick E. 1993. Experiments with fission yeast: A laboratory course manual. Cold Spring Harbor Laboratory Press, Cold Spring Harbor, NY.

Allo M, Buggiano V, Fededa JP, Petrillo E, Schor I, de la Mata M, Agirre E, Plass M, Eyras E, Elela SA, et al. 2009. Control of alternative splicing through siRNA-mediated transcriptional gene silencing. Nat Struct Mol Biol 16: 717-724.

Bahler J. 2005. Cell-cycle control of gene expression in budding and fission yeast. Annu Rev Genet 39: 69-94.

Bayne EH, White SA, Kagansky A, Bijos DA, Sanchez-Pulido L, Hoe KL, Kim DU, Park HO, Ponting CP, Rappsilber J, et al. 2010. Stc1: a critical link between RNAi and chromatin modification required for heterochromatin integrity. Cell 140: $666-677$.

Buker SM, Iida T, Buhler M, Villen J, Gygi SP, Nakayama J, Moazed D. 2007. Two different Argonaute complexes are required for siRNA generation and heterochromatin assembly in fission yeast. Nat Struct Mol Biol 14: 200-207.

Carmichael JB, Provost P, Ekwall K, Hobman TC. 2004. ago1 and dcrl, two core components of the RNA interference pathway, functionally diverge from rdpl in regulating cell cycle events in Schizosaccharomyces pombe. Mol Biol Cell 15: $1425-1435$.
Chen ES, Zhang K, Nicolas E, Cam HP, Zofall M, Grewal SI. 2008. Cell cycle control of centromeric repeat transcription and heterochromatin assembly. Nature 451: 734-737.

Claycomb JM, Batista PJ, Pang KM, Gu W, Vasale JJ, van Wolfswinkel JC, Chaves DA, Shirayama M, Mitani S, Ketting RF, et al. 2009. The Argonaute CSR-1 and its 22G-RNA cofactors are required for holocentric chromosome segregation. Cell 139: 123-134.

Emmerth S, Schober H, Gaidatzis D, Roloff T, Jacobeit K, Buhler M. 2010. Nuclear retention of fission yeast dicer is a prerequisite for RNAi-mediated heterochromatin assembly. Dev Cell 18: 102-113.

Grewal SI. 2010. RNAi-dependent formation of heterochromatin and its diverse functions. Curr Opin Genet Dev 20: 134141.

Gullerova M, Proudfoot NJ. 2008. Cohesin complex promotes transcriptional termination between convergent genes in S. pombe. Cell 132: 983-995.

Gullerova M, Moazed D, Proudfoot NJ. 2011. Autoregulation of convergent RNAi genes in fission yeast. Genes Dev (this issue). doi: $10.1101 / \mathrm{gad} .618611$.

Halic M, Moazed D. 2010. Dicer-independent primal RNAs trigger RNAi and heterochromatin formation. Cell 140: 504516.

Hansen K, Birse CE, Proudfoot NJ. 1998. Nascent transcription from the nmt1 and nmt2 genes of Schizosaccharomyces pombe overlaps neighbouring genes. EMBO J 17: 3066-3077.

Hirano M, Hirano T. 2006. Opening closed arms: long-distance activation of SMC ATPase by hinge-DNA interactions. Mol Cell 21: 175-186.

Hong EJ, Villen J, Gerace EL, Gygi SP, Moazed D. 2005. A cullin E3 ubiquitin ligase complex associates with Rik1 and the Clr4 histone H3-K9 methyltransferase and is required for RNAimediated heterochromatin formation. RNA Biol 2: 106-111.

Horn PJ, Bastie JN, Peterson CL. 2005. A Rik1-associated, cullin-dependent E3 ubiquitin ligase is essential for heterochromatin formation. Genes Dev 19: 1705-1714.

Jia S, Kobayashi R, Grewal SI. 2005. Ubiquitin ligase component Cul4 associates with Clr4 histone methyltransferase to assemble heterochromatin. Nat Cell Biol 7: 1007-1013.

Kloc A, Martienssen R. 2008. RNAi, heterochromatin and the cell cycle. Trends Genet 24: 511-517.

Kloc A, Zaratiegui M, Nora E, Martienssen R. 2008. RNA interference guides histone modification during the $S$ phase of chromosomal replication. Curr Biol 18: 490-495.

Martienssen RA, Zaratiegui M, Goto DB. 2005. RNA interference and heterochromatin in the fission yeast Schizosaccharomyces pombe. Trends Genet 21: 450-456.

Misulovin Z, Schwartz YB, Li XY, Kahn TG, Gause M, MacArthur S, Fay JC, Eisen MB, Pirrotta V, Biggin MD, et al. 2008. Association of cohesin and Nipped-B with transcriptionally active regions of the Drosophila melanogaster genome. Chromosoma 117: 89-102.

Motamedi MR, Verdel A, Colmenares SU, Gerber SA, Gygi SP, Moazed D. 2004. Two RNAi complexes, RITS and RDRC, physically interact and localize to noncoding centromeric RNAs. Cell 119: 789-802.

Motamedi MR, Hong EJ, Li X, Gerber S, Denison C, Gygi S, Moazed D. 2008. HP1 proteins form distinct complexes and mediate heterochromatic gene silencing by nonoverlapping mechanisms. Mol Cell 32: 778-790.

Nakayama J, Klar AJ, Grewal SI. 2000. A chromodomain protein, Swi6, performs imprinting functions in fission yeast during mitosis and meiosis. Cell 101: 307-317.

Noma K, Sugiyama T, Cam H, Verdel A, Zofall M, Jia S, Moazed D, Grewal SI. 2004. RITS acts in cis to promote RNA 
interference-mediated transcriptional and post-transcriptional silencing. Nat Genet 36: 1174-1180.

Parelho V, Hadjur S, Spivakov M, Leleu M, Sauer S, Gregson HC, Jarmuz A, Canzonetta C, Webster Z, Nesterova T, et al. 2008. Cohesins functionally associate with CTCF on mammalian chromosome arms. Cell 132: 422-433.

Stedman W, Kang H, Lin S, Kissil JL, Bartolomei MS, Lieberman PM. 2008. Cohesins localize with CTCF at the KSHV latency control region and at cellular c-myc and H19/Igf2 insulators. EMBO J 27: 654-666.

Sugiyama T, Cam HP, Sugiyama R, Noma K, Zofall M, Kobayashi R, Grewal SI. 2007. SHREC, an effector complex for heterochromatic transcriptional silencing. Cell 128: 491-504.

van Wolfswinkel JC, Claycomb JM, Batista PJ, Mello CC, Berezikov E, Ketting RF. 2009. CDE-1 affects chromosome segregation through uridylation of CSR-1-bound siRNAs. Cell 139: 135-148.

Verdel A, Jia S, Gerber S, Sugiyama T, Gygi S, Grewal SI, Moazed D. 2004. RNAi-mediated targeting of heterochromatin by the RITS complex. Science 303: 672-676.

Wendt KS, Yoshida K, Itoh T, Bando M, Koch B, Schirghuber E, Tsutsumi S, Nagae G, Ishihara K, Mishiro T, et al. 2008. Cohesin mediates transcriptional insulation by CCCTCbinding factor. Nature 451: 796-801.

Woolcock KJ, Gaidatzis D, Punga T, Buhler M. 2011. Dicer associates with chromatin to repress genome activity in Schizosaccharomyces pombe. Nat Struct Mol Biol 18: 94-99. 


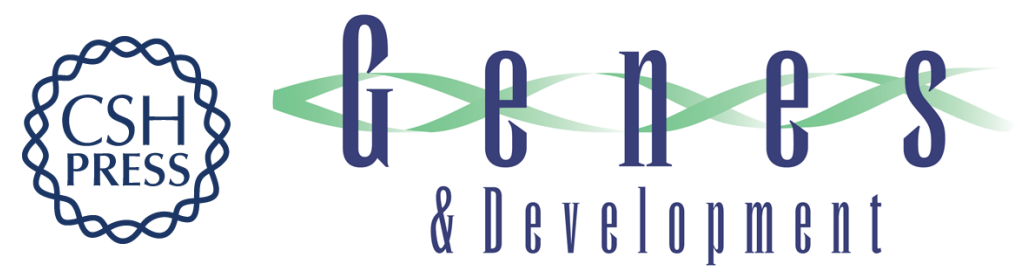

\section{RNAi genes pave their own way}

Leonie M. Kamminga and René F. Ketting

Genes Dev. 2011, 25:

Access the most recent version at doi:10.1101/gad.2038611

Related Content Autoregulation of convergent RNAi genes in fission yeast

Monika Gullerova, Danesh Moazed and Nick J. Proudfoot

Genes Dev. March , 2011 25: 556-568

References This article cites 31 articles, 4 of which can be accessed free at:

http://genesdev.cshlp.org/content/25/6/529.full.html\#ref-list-1

Articles cited in:

http://genesdev.cshlp.org/content/25/6/529.full.html\#related-urls

\section{License}

Email Alerting

Receive free email alerts when new articles cite this article - sign up in the box at the top

Service

right corner of the article or click here.

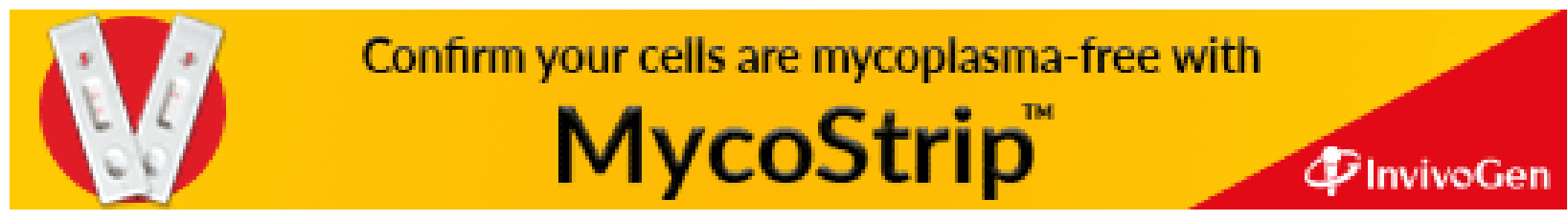

